\title{
Research on Brand Construction of Jingzhou Tourism Commodities Zhang Hong ${ }^{1}$ Feng Ding ${ }^{1}$ Gan Lu$^{2}$ Liu Xuhui ${ }^{1}$ Jia Hongyu $^{1}$
}

${ }^{1}$ School of Mechanical Engineering, Yangtze University, Jingzhou Hubei, China ${ }^{2}$ School of Art, Yangtze University, Jingzhou Hubei, China

\begin{abstract}
:
Although Jingzhou, with a long history, has rich tourism resources, it hasn't a "stunning" brand of tourism commodities. This article believes that, at the same time must both "tourism shopping brands" and "tourism commodity brands" be built in Jingzhou. According to the extensive investigation and analysis of its existing tourism resources and tourism commodity markets, implementation strategies of the Jingzhou tourism shopping brands, construction contents and strategies of Jingzhou tourism commodity brands are put forward, so as to make recommendations for promoting the development and brand construction of Jingzhou tourism commodities.
\end{abstract}

Keywords: Jingzhou; tourism commodities; brand construction

For a long time, shopping tourism has been a relatively weakness among Jingzhou tourism elements. Although Jingzhou with a long history of culture is rich in tourism resources, but have not a "stunning" brand of tourism commodities. Relying on the resources and geographical advantages, in recent years, Jingzhou has been concentrating on the construction of tourism industry. There are many problems still exist even though it has obtained certain achievements. The distance there is a big gap of domestic tourism province, how to shorten the gap is the most important topic which related to Jingzhou tourism and economic and social development of the whole city. Implementing the brand strategy of tourism commodities, especially combined with the regional culture closely, building famous brand, improving the proportion of tourist shopping in tourism revenue, increasing the tourists' non-essential tourism consumption, accelerating the pace of development of Jingzhou tourism commodity industry and establishing the image of Jingzhou tourism shopping will be core contents of tourism commodity industry development in Jingzhou. At the same time must both "Jingzhou tourism shopping brands" and "Jingzhou tourism commodity brands" be built. The two brands are like two sides of a coin, coexisting and indispensable.

\section{Building "Jingzhou Tourism Shopping Brands" Positively}

\subsection{The Definition of Tourism Shopping Brands}

Tourism shopping brands are used to identify regional tourism shopping industry or tourism shopping market. The tourism shopping brand in contents is

\footnotetext{
* This research is supported by Social Science Fund Project of Hubei Province in 2013 namely Research on Development and Design of Tourism Commodities with Jingchu Features, the project of Personnel Training Plan of Strategic Emerging (Pillar) Industry, the project of Comprehensive Reform of Speciality of the Ministry of Education - Autodesk Inc in 2012 namely The Comprehensive Reform of Industrial Design Specialty of Yangtze University(Grant NO.72), the University-level Key Project on Teaching in 2012 namely Research and Practice of Industrial Design Specialty Training Mode(Grant NO. JY2012007)
} 
much richer than the single tourism commodity brand. It includes following aspects such as the characteristics of tourism product sold in the market, the price level, the traffic, the market prosperity, the development level of local tourism, the market order, comprehensive shopping environment and so on.

In general, because any tourist has a certain degree of demand of tourist shopping, as long as the local tourism industry is carried out, driven by economic interests, travel products sales will be made by businesses or individuals. But because of the small scale and lack of proper management and guidance, more importantly, without a certain brand of tourist shopping, it's difficult to develop into industrial scale or form tourism shopping industry. The tourism development around the world fully demonstrates that if there are no wellknown tourism shopping brands, there can be no prosperous tourist shopping industry, even if there are the best tourism commodities. Even it often appears the condition that local tourism commodity is salable on the market in the field, namely "wall flower wall incense".

\subsection{Implementation Strategies of Jingzhou Tourism Shopping Brands}

Tourism shopping brand contains a large number of travel products and companies in the range. It is a total brand, and impossible for one or a few companies to monopolize. The site selection, the design of the whole environment style, the associated traffic condition and so on, must be planned, designed and constructed mainly by the government. As a result, the strategy of government guidance must be implemented to build Jingzhou tourist shopping brands.

\subsubsection{Concept Guidance}

Backward ideas could not develop the advanced social economy, so the
Jingzhou government should set up correct concept of government guidance to instruct construction and development of Jingzhou tourist shopping brands from the laws and requirements of market economy.

\subsubsection{Policy Guidance}

Although the policy is not the root cause of the economic development, favorable, flexible and fair policies and regulations can greatly promote the construction and development of Jingzhou tourist shopping brands. Policy guidance should follow the following three requirements.

(1) Completeness and flexibility. Relevant policies and regulations should be complete and have rules to follow. Considered that development of the tourism shopping industry is in a new field, the policies and regulations should maintain certain flexibility.

(2) Preferential. Tourism shopping industry has a vital significance for the local tourism and social economy development, so it is necessary to give appropriate policy support in the early stage of development.

(3) Fairness. Discount for a company is likely to be unfair and discriminatory against other companies. So providing a fair policy environment is very important.

\subsubsection{Management guidance}

Industry management is the basic function of government, and management guidance is the direct reflection of government guidance strategies. Management guidance mainly includes the construction of tourism shopping market, order management of the market and the corresponding training, etc.

\subsubsection{Propaganda guidance}

Propaganda is very important for the formation of a brand. Because the enterprises can't actively make efforts for the propaganda of tourist shopping brand, the propaganda must be carried out to 
build a well-known brand of Jingzhou tourism shopping by the government.

\section{Fully Operating "Jingzhou Tourist Commodity Brands"}

Jingzhou was called Jiangling City in ancient times which is located in southcentral of Hubei Province, the central city of Jianghan plain. It was the capital of $\mathrm{Chu}$ in history and it was a famous ancient battlefield of the Three Kingdoms. The events of "Liu Bei borrowed Jingzhou", "Guan Yu lost Jingzhou carelessly " and other popular stories in The Three Kingdoms took place here. It is the national famous historical and cultural city. Jingzhou is the main birthplace of Chu culture and Three Kingdoms culture. Many resorts, such as Point Sets, Riding Mountain, Poison Office of Guan Gong Guagu, Guan Gong Horsepond and A Bear Soil Site if Zhang Fei, have left the resonant three stories in the war. The famous ancient city of Jingzhou is surrounded by the Yangtze River tributaries and inland lakes. It has many cultural landscapes such as ancient city walls, JiNanCheng, Guan Gong Temple, ZhangHua Temple, Ancient Battlefield of Wulin, Huarong Road and so on. Jingzhou, with abundant tourism resources, has a broad development market and a unique advantage to develop tourist commodities. Therefore, the government should introduce the corresponding preferential policies for tourism commodity production enterprising, establishing and improving the tourism products development, production and sale of market mechanism and establishing a tourist shopping center. The tourism products are good and inexpensive. The government needs to strengthen market supervision and cooperation with other cities at the same time, and then the travel products will be built into the tourism trademark in the whole city and even the whole province.
That will enhance Jingzhou tourism attraction and promote the development of Jingzhou industry. Finally, Jingzhou tourism commodity brand will become bigger and stronger.

\subsection{Building the tourism commodity brand of Bronze culture}

Bronze culture is one of the main body of "Jing Chu" culture. The bronze ritual vessels is the most important part of the Chu bronze. Pan Wen Chi engraved mirror, which was unearthed from Chu tomb No. 201 in Zhangjiashan of Jiangling, and the Painted Bronze Mirror, which was unearthed from $\mathrm{Chu}$ tomb in Wangshan of Jiangling, are beautifully patterned and have a strong artistic appeal. To design a series of moral tradition classic tourist commodities with the core of Bronze culture and to design the tourism products according to Bronze Wares inheritance of Jing-Chu culture with the representative of Ding, Gui, Dun, $\mathrm{Hu}$, Fou, Glass and so on, will help to build the tourism commodity brand of Bronze culture.

\subsection{Building the tourism commodity brand of Lacquer culture}

Chu live with lacquerwares and will die without lacquerwares. Daily appliances and entertainment supplies used in their life are lacquer wares, and funeral supplies after their death used are also lacquer wares. Around crafts such as lacquered wooden seat screens, and daily appliances such as lacquered cups, lacquered bowls, lacquered beans, lacquered boxes, lacquered spoons and so on, and entertainment appliances such as lacquered drums, lacquered pianos, lacquered bamboo flutes and so on, and funeral supplies such as lacquered tomb beast, lacquered wooden figurines, lacquered coffins and so on, and also Gods images such as tomb animals, Tiger Tower-Flying Bird, and so on, a series of tourism commodities, which can interpret 
colorful Lacquer culture, highlight process characteristics and artistic characteristics of lacquerwares, be high artistic, decorative, monumental, ornamental and practical, are designed to build the tourism commodity brand of Lacquer culture.

\subsection{Building the tourism commodity brand of silk and embroidery culture}

Jingzhou of Hubei Province is a major Chu silk centre in archaeological discovery, Jiangling Mashan Tomb No. 1 is known as the "treasure-house of silk", unearthed 12 varieties of silk, 55 pieces of silk fabrics, more than 10 kinds of different pattern of Kam, dozens of different colors, a variety of weaving grains mainly with geometric lines, more than 10 kinds of embroidery decorations with people and animals pattern. The varieties of silk goods, fine crafts and good preservations are all unprecedented. Such rich and valuable resources do provide valuable materials for the development of Jingzhou tourist commodities. By full use of silk cultural relics, deep excavation its weaving technology, dyeing, color aesthetics, textured skills, ornamentation pattern and its underlying cultural themes, and creating a series of unique and elaborate tourism commodities, the tourism commodity brand of silk and embroidery culture will be built.

\subsection{Building the tourism commodity brand of Currency culture}

Chu has the currency of "Three Money", namely the metal currency. Coppers are mainly copper, elliptic, flat on the back and front projection with text, font like ants, two like nostrils, therefore called YiBiQian. And it looks like Bei, like the ancient prose "bei" word, like a face, so it is also called "Grimace Money". Around Chu coins like YiBiQian, a series of tourism commodities, which can interpret and inherit business culture, currency culture, casting process and morphology evolution are designed to build the tourism commodity brand of Currency culture.

\subsection{Building the tourism commodity brand of Military culture}

Around the Three Kingdoms culture such as Chu army composition, military preparation, military tactics, military weapons and so on, a series of unique and elaborate, cultural, memorial and practical tourism commodities are designed to build the tourism commodity brand of Military culture.

\subsection{Building the natural and ecological tourism commodity brand}

We can employ natural and ecological environment with the plain south, hilly north and people-water harmony to design a series of tourism commodities with unique landscape characteristics and folk customs, so as to build the natural and ecological tourism commodity brand.

\section{Construction Strategies of Jingzhou Tourism Commodity Brands}

\subsection{Brand positioning of Jingzhou tourism commodities}

\subsubsection{Focusing on the core value of Jingzhou tourism commodities}

The core value of brand is the soul of the brand, the most fundamental interests of the brand promising to consumers and the driving force of prompting the visitors to identify with, like and even be loyal to a brand. Whoever wants to shape a golden brand must plan the core value of the brand. The core value of brand is the strategic target of brand construction and the original point of the brand marketing activities. Looking for the core value of Jingzhou tourism commodities needs to 
start from the following four aspects such as looking for the differentiation, seeking out tourists' identity, exploring the brief and single pursuit point of the brand and implementing strategical thought.

\subsubsection{Positioning the brand of} Jingzhou tourism commodities well

Brand positioning must be closely around the core value of the brand and root the core value of tourism commodities in the hearts of tourists. Positioning is the tactics of psychological offense and the tactics into tourists' minds. The successful brand positioning, firstly, can make differences and features, secondly, is the market's guide, thirdly, is clear and not ambiguous, and lastly, is long-term and not arbitrarily changed.

(1) Positioning the brand of Jingzhou tourism commodities can abide by the following four steps. Firstly, industry environment of Jingzhou tourism commodities should be analyzed. Secondly, the concept of distinction should be looked for. Thirdly, the supporting point should be sought out. At last, the brand should be spread and applied.

(2) One or several kinds of the following ten kinds of modes can be adopted to position the brand of Jingzhou tourism commodities such as contrasted positioning, positioning on the base of commodity function, positioning on the base of price, positioning on the base of commodity appearance, positioning on the base of innovation, positioning on the base of service, positioning on the base of national brands, positioning on the base of consumption background, positioning on the base of the good image of brand and positioning on the base of customers image.

\subsection{Brand strategies of Jingzhou tourism commodities}

Brand strategies of Jingzhou tourism commodities can be selected from the following four modes: (1) The strategy of one product with several brands, which is the closest to commodities and the minimal scope of covering commodities. (2) The strategy of one product with one brand, which means different categories of goods are given different brands. (3) The brand strategy of classification, which means that all kinds of commodity use different brands in the foundation of classification of all the goods. (4) The brand strategy of uniform, which means that many different categories of commodities share the same brand.

\subsection{Strengthening brand management and adjusting the structure of the brand}

\subsubsection{Vigorously promoting the} brand with strong profitability and growth

In terms of its profitability and growth, the brand can be divided into four categories such as the star-class brand with both high growth and profitability, the Taurus-class brand with low growth but high profitability, the question-markclass brand with high growth but low profitability, and the thin-dog-class brand with both low growth and profitability. Four categories provide the foundations for tourism commodity brand management and brand layout. The management should mainly advocate the star-class brand and the Turus-class brand, and suitably advocate the question-markclass brand.

3.3.2. Making good brand positioning and strengthening the brand management

In terms of brand market share and goods market nature, the structure of the brand includes the following four types such as the brand likened to thumbing a ride with high grade goods but low market share, the brand likened to the high road with both high grade goods and high market share, the brand likened to the low road with low grade goods but 
high market share, and the brand likened to blind alley with both low grade goods and low market share.

The government should vigorously develop the brand of low road based on the characteristic of the tourism commodity and the brand structure. Establish the management office of Jingzhou tourism commodity brands and solve the actual problems for enterprises.

\subsection{Actively exploring and working out the plight of creating the brand of local specialty}

As the local specialties including food, tea, wine, medicine, products of animal husbandry and other agricultural and sideline products are restricted to factors such as the natural environment, the low industrialization degree and the outstanding contradiction of "Small-scale production and big market", there is a considerable difficulty in the brand operation. But the branding of the local specialty complies with the requirement of era development. The branding of the local specialty is the inevitable choice that the local specialty changes from shortage to relative surplus.

In order to make the local specialty walk to the road of branding, the following measures can be taken: (1) The local specialty can choose to register brand marks, certification marks and collective marks. (2) Setting up various forms of local specialty industrialization organization. (3) Improving and maintaining the quality of the local specialties and making good brand foundation. (4) Carrying out special promotion and enhancing the awareness of the brand; (5) Paying attention to the commodity packaging and lifting the worth of the local specialty. (6) Paying attention to the elaborate processing and pulling out the product series of miniaturization.

\subsection{Strengthening the communication of brand}

The core value of the brand must be tightly hold and commodity positioning should be combined in the process of the communication of the brand of Jingzhou tourism commodities. At first, a sound enterprise and product image system should be established easy to identify for tourists. Then a good brand personality system should be made for tourism commodity differentiation and conceptualization demands. Again, perfect brand association system should be built to hold tourists psychological needs tightly. In the end, both "tourism shopping brands"and "tourism commodity brands"should be brought into publicity-oriented plan in the whole city.

\section{References}

[1] Wang Qingsheng. Tourism Project Planning Course [M]. Tsinghua University Press, 2013.07

[2] Fang Baishou. Study on Tourism Commodities [M]. Mechanical Industry Press, 2008.07

[3] Huang Jing. Brand Marketing [M]. Peking University Press, 2008.11

[4] Peng Diefei. Marketing Strategies of Regional Tourism Commodities [J]. Economic Geography. 2006,3:526 529

Zhang Hong. Research on Countermeasures of Chinese Tourist Commodities Development.2010 IEEE 11th International Conference on Computer-aided Industrial Design \& Conceptual Design. IEEE PRESS. 2010, 11: $1410 \sim 1412$ 